\title{
Nursing and Dental Students' and Pediatric Dentistry Residents' Responses to Experiences with Interprofessional Education
}

\author{
Gail A. Czarnecki, D.D.S.; Stephanie J. Kloostra, D.D.S.; James R. Boynton, D.D.S., M.S.; \\ Marita R. Inglehart, Dr. phil. habil.
}

Abstract: Interprofessional education (IPE) has received increasingly more attention over recent years. The objectives of this study were to assess 1) how nursing students' considerations concerning their own oral health and oral health-related knowledge changed from before to after experiencing IPE; 2) how nursing students', dental students', and pediatric dentistry residents' IPErelated attitudes and Readiness for Interprofessional Learning Scale (RIPLS) scores changed after experiencing an IPE rotation; and 3) how these groups' attitudes and RIPLS scores were related. Data were collected from three groups who participated in an IPE rotation: thirty-eight of forty third-year dental students (95 percent response rate), all thirty-three nursing students (100 percent), and all six pediatric dentistry residents (100 percent) prior to the rotation, and 100 percent of each group after the rotation. As a control group, data were also collected at the beginning of the winter term from first-year dental students (104 out of 105; 99 percent response rate) and second-year dental students (102 out of 116; 88 percent); the same groups were surveyed at the end of term, with response rates of 98 percent for first-year students and 89 percent for second-year students. After the rotation, the nursing students' tooth brushing frequency increased, and their comfort level with dental visits and oral health-related knowledge improved. The dental students rated the importance of nurses' having oral health-related knowledge and skills lower than did the nursing students and pediatric dentistry residents. The groups' RIPLS scores correlated with these importance ratings. Overall, while the nursing students showed positive responses to IPE, the dental students' attitudes and RIPLS scores did not change as a result of the IPE experience. Future research should explore the conditions under which dental students are impacted by IPE.

Dr. Czarnecki is Adjunct Clinical Assistant Professor, Department of Orthodontics and Pediatric Dentistry, School of Dentistry, University of Michigan and in private practice as a pediatric dentist in Oak Brook, IL; Dr. Kloostra is Pediatric Dental Resident, Department of Orthodontics and Pediatric Dentistry, School of Dentistry, University of Michigan; Dr. Boynton is Clinical Associate Professor and Director of Pediatric Dentistry, Department of Orthodontics and Pediatric Dentistry, School of Dentistry, University of Michigan; and Dr. Inglehart is Professor, Department of Periodontics and Oral Medicine, School of Dentistry, and Adjunct Professor, Department of Psychology, College of Literature, Science, and Arts, University of Michigan. Direct correspondence and requests for reprints to Dr. Marita R. Inglehart, Department of Periodontics and Oral Medicine, University of Michigan School of Dentistry, 1011 N. University Ave., Ann Arbor, MI 48109-1078;734-763-8073; mri@umich.edu.

Keywords: interprofessional education, dental education, nursing education, dental students, nursing students, pediatric dentistry, Readiness for Interprofessional Learning Scale

Submitted for publication 10/26/13; accepted 1/28/14

I n the year 2000, the U.S. surgeon general's report on oral health drew attention to the fact that children's oral health and access to oral health care services need to be improved. ${ }^{1}$ One way to increase the prevention of oral disease among children and improve oral health promotion efforts would be to engage pediatricians and nurses in oral health screenings, oral health education efforts, and referrals when parents bring their children to regularly scheduled well visits. Additionally, pediatricians and pediatric nurses who care for the more than six million children who are hospitalized in the United States every year ${ }^{2}$ could use these interactions to address oral health care needs. Studies have found that many of these children engaged inadequately or not at all in oral health behavior ${ }^{3,4}$ and that 40 percent of hospitalized children had unmet oral health care needs. ${ }^{5}$ Preexisting oral health problems may be exacerbated under these circumstances, and additional oral complications might occur as side effects of medical conditions, treatments, and use of medications. ${ }^{6-8}$ Oral hygiene efforts might be seen as less important than coping with medical problems and might therefore be neglected. ${ }^{6}$ It is not surprising to find that medically compromised children have been reported to experience a high rate of dental disease $e^{9,10}$ and to be at increased risk of developing systemic complications from dental infections, which may prove fatal. ${ }^{7}$ Nurses can play an important role in this context because they provide supportive care during 
pediatric patients' hospital stays and communicate with parents about their children's needs. However, oral care has been shown to be a low priority for nurses, ${ }^{8,11}$ and many nursing students and nurses have been found to have a low level of understanding of oral health issues, ${ }^{12,13}$ which is most likely related to the finding that nursing education has not been likely to focus on oral health issues. ${ }^{14-16}$

Interprofessional education (IPE) might be one way to change this situation for nurses, while at the same time educating future dental care providers about the importance of interprofessional collaboration. Formicola et al. pointed out that this perspective is supported by several considerations. ${ }^{17}$ The first describes dentistry as part of the primary care system and thus requires dentists to be able to successfully communicate with other primary care providers; additionally, chronic health conditions such as diabetes not only have consequences for oral health, but oral health might even affect these conditions. According to Formicola et al., also important in this context are the facts that effective oral health care can best be achieved when oral health care providers collaborate with other members of the health professions and that dentists are expected to interact with the community public health system to improve access to care and implement preventive oral care services.

Based on these considerations, a new program was developed at the University of Michigan to provide an opportunity for third-year dental students and pediatric dentistry residents to interact with nursing students in an interprofessional educational experience in a pediatric dental clinic. The purpose of the evaluation research accompanying this study was first to gain a better understanding of how this IPE experience affected the nursing students' oral healthrelated behavior and oral health-related knowledge and skills. Based on social-psychological theories concerning the relationship between attitudes and behaviors, ${ }^{18}$ we predicted that once these nursing students were immersed in the pediatric clinic environment and exposed to the dominant norms that support proper oral hygiene and stress the importance of good oral health promotion efforts, it would affect their own oral health-related behavior, such as their own tooth brushing. In addition, the educational efforts should result in improved oral health-related knowledge and skills.

Second, this study aimed at gaining a better understanding of how IPE experiences affect the IPE-related attitudes and Readiness for Interdisciplinary Learning Scale (RIPLS) scores of both the nursing students and the predoctoral and graduate dental students. The second objective therefore was to assess whether the IPE experience would improve nursing students', dental students', and pediatric dentistry residents' IPE-related attitudes as well as their RIPLS scores ${ }^{19}$ from the beginning to end of this IPE experience compared to the scores of first- and second-year dental students who did not participate in the IPE experience. Additionally, we explored whether IPE-related attitudes and RIPLS scores were related.

\section{Methods}

This study was approved by the Institutional Review Board for the Behavioral and Health Sciences at the University of Michigan. Thirty-three first-year nursing students and forty third-year dental (D3) students participated in an IPE experience in a pediatric dentistry clinic together with six pediatric dentistry residents during the winter term of 2013. To assess changes, we surveyed all three groups before and after the rotation. Control group data were collected from first-year (D1) and second-year (D2) dental students at the beginning and end of the winter term.

Students in the control group were surveyed near the beginning of the term in January and during the last week of the term in April. A member of the research team informed students about the study at the end of regularly scheduled dental school classes and asked if they would volunteer to respond to a survey and return it to the research team anonymously. Data from the nursing students and D3 students who participated in the IPE experience were collected when they arrived on Monday morning of the first week of their rotations in the pediatric dentistry clinic and at the end of the last day of their rotations. All six pediatric dentistry residents in this clinic responded to the survey at the beginning and end of the winter term.

\section{Key Features of IPE Program}

This IPE program in the pediatric dentistry clinic was developed and first implemented in the winter term 2013. Nursing students participated for one week in groups of three to five students. They collaborated with the D3s and pediatric dentistry residents in providing care for pediatric patients.

When the nursing students arrived on Monday morning, they received the pre-rotation survey followed by an overview of the rotation activities. 
The students then went on a tour of the pediatric dentistry clinic and were introduced to faculty and staff members. A twenty-minute lecture introducing them to the specialty of pediatric dentistry followed. The students then had a two-hour opportunity to shadow the D3s and residents who were providing care to pediatric patients, followed by a debriefing session. The other mornings began with a one-hour classroom-based activity at 8 a.m. before the clinics opened; it included presentations on caries risk assessment and prevention strategies, health education, and how to provide care for patients with special health care needs. These classroom-based activities were always followed by a two-and-a-half-hour shadowing period and a thirty-minute small-group session with the D3s before the lunch break. At 1 p.m., the nursing students again shadowed the D3s and pediatric dentistry residents and then participated in a one-hour classroom-based activity, which consisted of discussing additional topics such as perinatal counseling and infant oral health exams plus debriefing them. In addition, the students watched three videos: "Child Abuse and Neglect," "Caries Risk Assessment," and "Infant Oral Health Examination." They also were encouraged to read certain articles as well as chapters in McDonald and Avery's textbook Dentistry for the Child and Adolescent. ${ }^{20}$ In summary, each of their days included didactic activities with or without the D3s and mostly consisted of observing and collaborating with the D3s and residents in the clinics.

The D3 students participated in the pediatric dentistry rotation for five weeks. Four groups of dental students participated in the IPE experience; each group consisted of about ten students. On the morning of the first day of their rotation, they completed the pre-rotation survey. An average day of their rotations consisted of patient care between 9:00 a.m. and 11:30 a.m. and between 2:00 p.m. and 4:00 p.m. They also participated in twice daily seminars on diagnosis and treatment planning and engaged in small-group discussions of relevant topics with the nursing students. During patient care, the nursing students observed these D3s and delivered oral hygiene instruction to their patients. They also applied fluoride varnish under the guidance of faculty members.

The pediatric dentistry residents completed a pre-rotation survey and worked with the nursing students during patient care. The residents shared their knowledge of pediatric dentistry and helped engage the nursing students during their rotation.

\section{Materials}

The nursing students' survey consisted of five sets of questions. Part 1 asked for general background information such as gender and age. Part 2 included questions concerning the students' own oral healthrelated behavior such as how often they brushed their teeth and how comfortable they were with going to the dentist. Part 3 consisted of knowledge questions related to children's oral health and oral health care, such as whether they had sufficient knowledge to perform oral health screenings or oral hygiene procedures, provide fluoride varnish, or engage in oral health education. Part 4 consisted of twenty attitudinal items asking respondents to rate how important it is for nurses to learn oral health-related knowledge and skills. The respondents indicated their disagreement/agreement with these statements on a five-point scale ranging from $1=$ disagree strongly to $5=$ agree strongly.

The responses to the twenty attitudinal items were factor analyzed (extraction method: principal component analysis; rotation method: Varimax rotation). The results showed that the items loaded on four factors. Six items loaded on Factor 1, which can be described as the "Importance of nurses' having knowledge about the relationship between oral and systemic health" (Cronbach alpha at Time 1: 0.916; at Time 2: 0.931). Six items loaded on Factor 2 that captures the "Importance of nurses' having clinical skills" (Cronbach alpha at Time 1: 0.903; at Time 2: 0.954). Five items loaded on Factor 3, which can be described as the "Importance of nurses' considering oral health in clinical settings" (Cronbach alpha at Time 1: 0.824; at Time 2: 0.875). The final three items loaded on Factor 4, which captures the "Importance of nurses' having the skills to recognize oral disease" (Cronbach alpha at Time 1: 0.913; at Time 2: 0.926). The inter-item consistency coefficients showed that scales 1,2 , and 4 had excellent reliability and that the third scale had good reliability. ${ }^{21}$ Indices could therefore be constructed.

The fifth part of the survey consisted of the Readiness for Interprofessional Learning Scale (RIPLS). This scale, developed by Parsell and Bligh, ${ }^{19}$ consists of nineteen Likert-style items that represent three subscales. The first scale, "Teamwork and Collaboration," consists of nine items that assess respondents' beliefs that shared learning is beneficial. The second subscale, "Professional Identity," consists of seven items that assess respondents' readiness to learn about professional identity issues. The final 
subscale, "Roles and Responsibilities," consists of two items.

The results of a factor analysis (extraction method: principal component analysis; rotation method: Varimax rotation) of the answers in this study supported Parsell and Bligh's findings. ${ }^{19}$ Indices for the three subscales were therefore computed. The Cronbach alpha inter-item consistency values for the three subscales at Time 1 and Time 2 showed that the reliability of the first subscale was excellent and the reliability of the second subscale was good. ${ }^{19}$ However, the reliability of the third subscale was questionable.

The surveys for the dental students and pediatric dentistry residents did not include the questions from Part 2 of the nursing students' questionnaire concerning personal oral health-related issues or the questions from Part 3 about oral health-related knowledge. However, all other questions concerning background (Part 1), importance ratings (Part 4), and the RIPLS scale (Part 5) were included in their surveys.

\section{Statistical Analyses}

The data were analyzed with SPSS (Version 19). Descriptive statistics such as frequency distributions, percentages, means, and standard devia- tions were computed to provide an overview of the responses. Paired sample t-tests and chi-square tests were used to compare the nursing students' before and after responses concerning their own oral health, oral health behavior, and knowledge. Multivariate analyses of variance were used to compare responses to the items loading on specific factors of the different groups of respondents at the baseline and end of the intervention/term. Pearson correlation coefficients were computed to assess the relationships between the RIPLS score indices and the four attitudinal factor indices. Independent sample t-tests were used to compare the program evaluation responses of the D3 students and the nursing students. A level of $p<0.5$ was accepted as significant.

\section{Results}

Table 1 provides an overview of the characteristics of the dental and nursing students and pediatric dentistry residents at Time 1 (T1): the beginning of winter term for the D1 and D2 students in the control groups, and the beginning of rotations for the D3s, nursing students, and residents. The response rates were excellent. In January (T1), 104 of the 105 D1 students ( 99 percent) and 102 of the 116 D2 students

\section{Table 1. Respondents' characteristics}

\begin{tabular}{|c|c|c|c|c|c|c|c|}
\hline & Intervention & Time & $\begin{array}{c}\text { D1 } \\
\text { Students }\end{array}$ & $\begin{array}{c}\text { D2 } \\
\text { Students }\end{array}$ & $\begin{array}{c}\text { D3 } \\
\text { Students }\end{array}$ & $\begin{array}{l}\text { Nursing } \\
\text { Students }\end{array}$ & $\begin{array}{l}\text { Pediatric } \\
\text { Dentistry } \\
\text { Residents }\end{array}$ \\
\hline \multirow[t]{4}{*}{$\begin{array}{l}\text { Number of students who participated } \\
\text { (response rate) }\end{array}$} & No rotation: January & T1 & $\begin{array}{c}104 \\
(99 \%)\end{array}$ & $\begin{array}{c}102 \\
(88 \%)\end{array}$ & - & - & - \\
\hline & Pre rotation & T1 & - & - & $\begin{array}{c}38 \\
(95 \%)\end{array}$ & $\begin{array}{c}33 \\
(100 \%)\end{array}$ & $\begin{array}{c}6 \\
(100 \%)\end{array}$ \\
\hline & Post rotation & $\mathrm{T} 2$ & - & - & $\begin{array}{c}40 \\
(100 \%)\end{array}$ & $\begin{array}{c}33 \\
(100 \%)\end{array}$ & $\begin{array}{c}6 \\
(100 \%)\end{array}$ \\
\hline & No rotation: April & $\mathrm{T} 2$ & $\begin{array}{c}103 \\
(98 \%)\end{array}$ & $\begin{array}{c}103 \\
(89 \%)\end{array}$ & - & - & - \\
\hline \multirow[t]{4}{*}{ Gender: \% female } & No rotation: January & T1 & $45 \%$ & $51 \%$ & - & - & - \\
\hline & Pre rotation & $\mathrm{T} 1$ & - & - & $47 \%$ & $73 \%$ & $83 \%$ \\
\hline & Post rotation & $\mathrm{T} 2$ & - & - & $45 \%$ & $73 \%$ & $86 \%$ \\
\hline & No rotation: April & $\mathrm{T} 2$ & $44 \%$ & $55 \%$ & - & - & - \\
\hline \multirow[t]{4}{*}{ Age: Mean (SD) } & No rotation: January & T1 & $\begin{array}{l}24.13 \\
(2.682)\end{array}$ & $\begin{array}{l}25.98 \\
(6.739)\end{array}$ & - & - & - \\
\hline & Pre rotation & T1 & - & - & $\begin{array}{c}26.17 \\
(0.814)\end{array}$ & $\begin{array}{c}27.82 \\
(0.839)\end{array}$ & $\begin{array}{c}27.63 \\
(1.703)\end{array}$ \\
\hline & Post rotation & $\mathrm{T} 2$ & - & - & $\begin{array}{l}25.95 \\
(0.741)\end{array}$ & $\begin{array}{l}27.82 \\
(0.916)\end{array}$ & $\begin{array}{c}27.38 \\
(1.657)\end{array}$ \\
\hline & No rotation: April & $\mathrm{T} 2$ & $\begin{array}{c}24.11 \\
(2.169)\end{array}$ & $\begin{array}{c}24.99 \\
(2.577)\end{array}$ & - & - & - \\
\hline
\end{tabular}


(88 percent) responded to the survey. In addition, thirty-eight of forty D3 students ( 95 percent), all thirty-three of the nursing students (100 percent), and all six of the pediatric dentistry residents (100 percent) responded to the survey prior to their rotation (T1). At Time 2 (T2), after their rotation, all forty D3 students, all thirty-three nursing students, and all six pediatric dentistry residents (100 percent of each group) responded to the survey. At the end of the term (T2), 103 of the $105 \mathrm{D} 1$ students (98 percent) and 103 of the 116 D2 students ( 89 percent) responded to the survey. While about half of the dental students were women, 73 percent of the nursing students and 86 percent of the pediatric dentistry students were women. The students were all in their twenties, with the D1s having an average age of twenty-four years, the D2s an average age of twenty-five to twenty-six years, and the D3s, nursing students, and residents an average age of twenty-six to twenty-eight.

The first aim focused on assessing whether the nursing students' perceptions of their own oral health, oral health behavior, and oral health-related knowledge changed from before (T1) to after (T2) the rotation. The results showed no significant change in the nursing students' description of their own oral health (Table 2). However, their frequency of tooth brushing increased significantly from $\mathrm{T} 1$ to $\mathrm{T} 2$. In addition, the nursing students indicated at $\mathrm{T} 2$ that they had been younger at the time of their first dental visit than they reported at T1 (T1: 3.68 years vs. T2: $3.14, \mathrm{p}=0.036$ ). When asked how they felt about go- ing to the dentist, a significant change was noted after the rotation, with 73 percent of the nursing students indicating at $\mathrm{T} 1$ that they were comfortable going to the dentist and 85 percent at $\mathrm{T} 2(\mathrm{p}=0.001)$.

The nursing students' knowledge also increased significantly from before to after the rotation (Table 3 ). When asked by which age pediatric patients should see a dentist, the average response at $\mathrm{T} 1$ was 2.48 years, while it shifted to less than one year at T2. When asked if they have sufficient knowledge to perform oral exams, provide fluoride varnish, engage in oral hygiene procedures, do a caries risk assessment, educate parents about oral health issues, and engage in prenatal oral health counseling, significantly higher percentages of the nursing students answered yes at $\mathrm{T} 2$ than at T1. A comparison of the average sum of yes answers at $\mathrm{T} 1$ with the average sum of yes answers at $\mathrm{T} 2$ showed that the overall knowledge scores increased from 0.39 yes answers out of six possible yes answers at $\mathrm{T} 1$ to 5.33 yes answers at $\mathrm{T} 2$.

The same pattern of results was found for answers to the questions whether the nursing students could diagnose seven oral disease-related conditions. When asked if they could identify dental caries, intraoral viral infections, intraoral fungal infections, mucositis, xerostomia, apthous ulcerations, and gingivitis, the results showed that the percentages of yes answers at $\mathrm{T} 1$ were lower for each condition than at T2. A comparison of the average sum of yes answers to these questions at $\mathrm{T} 1$ with the average sum of yes answers at T2 showed that these scores

Table 2. Nursing students' perceptions of their own oral health before and after rotation in the pediatric dental clinic

\begin{tabular}{|c|c|c|c|}
\hline Perceptions of Own Oral Health & $\begin{array}{l}\text { Before Rotation } \\
\text { Mean (SD) }\end{array}$ & $\begin{array}{c}\text { After Rotation } \\
\text { Mean (SD) }\end{array}$ & $\mathrm{p}$ \\
\hline How would you describe the health of your teeth and gums?a & $3.85(0.755)$ & $3.82(0.683)$ & 0.768 \\
\hline How often do you floss your teeth?b & $2.97(0.984)$ & $3.06(0.998)$ & 0.374 \\
\hline How old were you when you saw a dentist for the first time? & $3.68(2.589)$ & $3.14(2.642)$ & 0.036 \\
\hline Did you see a dentist during the last year? \% Yes & $79 \%$ & $79 \%$ & - \\
\hline $\begin{array}{l}\text { Think about how you feel about going to the dentist: } \\
\text { Comfortable } \\
\text { Apprehensive } \\
\text { Scared }\end{array}$ & $\begin{array}{c}73 \% \\
27 \% \\
0\end{array}$ & $\begin{array}{c}85 \% \\
15 \% \\
0\end{array}$ & 0.001 \\
\hline $\begin{array}{l}\text { Number of dental procedures: } \\
\text { Extractions } \\
\text { Fillings } \\
\text { Root canals } \\
\text { Crowns }\end{array}$ & $\begin{array}{l}1.28(2.374) \\
2.41(2.500) \\
0.31(0.592) \\
0.36(0.859)\end{array}$ & $\begin{array}{l}1.07(2.404) \\
2.63(2.691) \\
0.28(0.523) \\
0.42(0.867)\end{array}$ & $\begin{array}{l}0.375 \\
0.161 \\
0.325 \\
0.423\end{array}$ \\
\hline Do you have dental pain right now? \% Yes & $7 \%$ & $7 \%$ & - \\
\hline Do you have untreated dental disease? \% Yes & 0 & 0 & - \\
\hline
\end{tabular}


Table 3. Nursing students' oral health-related knowledge before and after their rotation in the pediatric dental clinic

\begin{tabular}{|c|c|c|c|}
\hline Oral Health-Related Knowledge & Before Rotation & After Rotation & $\mathrm{p}$ \\
\hline \multirow[t]{2}{*}{ By which age should pediatric patients see a dentist? Mean (SD) } & $\begin{array}{l}2.48 \text { years } \\
(1.101)\end{array}$ & $\begin{array}{l}0.920 \text { years } \\
(0.181)\end{array}$ & $<0.001$ \\
\hline & $\%$ Yes & $\%$ Yes & \\
\hline Can medical conditions affect pediatric patients' oral health? (yes) & $100 \%$ & $100 \%$ & - \\
\hline Can medications affect pediatric patients' oral health? (yes) & $100 \%$ & $100 \%$ & - \\
\hline Can medical treatments/interventions affect pediatric patients' oral health? (yes) & $97 \%$ & $100 \%$ & - \\
\hline Pediatric patients' oral health can affect their systemic health. (yes) & $100 \%$ & $100 \%$ & - \\
\hline \multicolumn{4}{|l|}{ Do you have sufficient knowledge to perform/provide: } \\
\hline Oral exams & 0 & $82 \%$ & \\
\hline Fluoride varnish & $9 \%$ & $94 \%$ & \\
\hline Oral hygiene procedures & $3 \%$ & $79 \%$ & \\
\hline Caries risk assessment & $6 \%$ & $94 \%$ & \\
\hline Oral health education & $15 \%$ & $100 \%$ & \\
\hline Prenatal oral health counseling & $6 \%$ & $85 \%$ & \\
\hline Average sum of "yes" responses & Mean $=0.39$ & Mean=5.33 & $<0.001$ \\
\hline \multicolumn{4}{|l|}{ Can you diagnose: } \\
\hline Dental caries & $15 \%$ & $94 \%$ & \\
\hline Intraoral viral infections & 0 & $33 \%$ & \\
\hline Intraoral fungal infections & $9 \%$ & $52 \%$ & \\
\hline Mucositis & $3 \%$ & $30 \%$ & \\
\hline Xerostomia (dry mouth) & $12 \%$ & $61 \%$ & \\
\hline Apthous ulceration & 0 & $21 \%$ & \\
\hline Gingivitis & $15 \%$ & $76 \%$ & \\
\hline Average sum of "yes" responses & Mean $=0.55$ & Mean=3.67 & $<0.001$ \\
\hline \multicolumn{4}{|l|}{ Is it recommended } \\
\hline -to brush baby teeth? (yes) & $94 \%$ & $100 \%$ & \\
\hline -to floss baby teeth? (yes) & $63 \%$ & $75 \%$ & \\
\hline Average sum of correct responses & Mean $=1.56$ & Mean $=1.75$ & - \\
\hline Is using a foam swab as effective as using a toothbrush? (no) & $72 \%$ & $91 \%$ & - \\
\hline $\begin{array}{l}\text { Is it important to give oral health instruction to caregivers of hospitalized } \\
\text { pediatric patients? (yes) }\end{array}$ & $100 \%$ & $100 \%$ & - \\
\hline Is it necessary to refer a pediatric patient if oral health problems are observed? (yes) & $100 \%$ & $100 \%$ & - \\
\hline
\end{tabular}

increased from 0.55 yes answers out of seven possible yes answers at $\mathrm{T} 1$ to 3.67 at $\mathrm{T} 2$. No significant differences between the responses at $\mathrm{T} 1$ and $\mathrm{T} 2$ were found concerning the answers to several questions such as whether medical conditions, medications, and medical treatment interventions can affect pediatric patients' oral health. For nearly all of these questions, the nursing students had arrived at the beginning of the rotation already having some solid background knowledge.

While the dental students and the pediatric dentistry residents did not answer any questions concerning their own oral health and oral health-related knowledge, they responded together with the nursing students to twenty questions asking how important it is for nurses to learn about oral health-related issues. A factor analysis of responses to these twenty items resulted in four factors, which can be described as the "Importance of nurses' realizing the relationship between oral and systemic health," "Importance of nurses' having clinical skills," "Importance of nurses' considering oral health in a clinical setting," and "Importance of nurses' having skills to recognize oral diseases." For each of these four sets of indicators, an index was computed by averaging the responses to the items loading on these factors at T1 and T2 (Table 4). The results showed that the main effect "Type of respondent" was significant for each of the four indices. In each case, the average responses of the nursing students and the residents were higher than the average importance indices of the D1s, D2s, and D3s.

However, when we analyzed the T1 vs. T2 differences in the responses of the students who participated in the rotations, only the nursing students showed the predicted improvement in their 
Table 4. Average importance ratings of dental, nursing students, and pediatric residents on items under four factors

\begin{tabular}{|c|c|c|c|c|c|c|}
\hline \multirow{2}{*}{ Factor/Item } & & \multicolumn{2}{|c|}{ No Rotation } & \multicolumn{3}{|c|}{ Rotation } \\
\hline & & $\begin{array}{l}\mathrm{D} 1 \\
\text { Students } \\
\mathrm{N}=91\end{array}$ & $\begin{array}{l}\mathrm{D} 2 \\
\text { Students } \\
\mathrm{N}=83\end{array}$ & $\begin{array}{l}\mathrm{D} 3 \\
\text { Students } \\
\mathrm{N}=36\end{array}$ & $\begin{array}{l}\text { Nursing } \\
\text { Students } \\
\mathrm{N}=33\end{array}$ & $\begin{array}{l}\text { Residents } \\
\mathrm{N}=5\end{array}$ \\
\hline \multicolumn{7}{|l|}{ Factor 1: Importance of relationship between oral and systemic health. } \\
\hline \multirow[t]{2}{*}{-learn about oral health issues in school. } & $\mathrm{T} 1$ & 4.41 & 4.40 & 4.50 & 4.55 & 5.00 \\
\hline & $\mathrm{T} 2$ & 4.34 & 4.47 & 4.47 & $4.79^{* *}$ & 4.40 \\
\hline \multirow{4}{*}{$\begin{array}{l}\text {-know about the relationship between oral health and systemic } \\
\text { health. } \\
\text {-know about how medical conditions affect children's oral health. }\end{array}$} & $\mathrm{T} 1$ & $4.67^{*}$ & 4.57 & 4.53 & $4.76^{* *}$ & 5.00 \\
\hline & T2 & 4.47 & 4.55 & 4.47 & 4.88 & 4.60 \\
\hline & $\mathrm{T} 1$ & 4.47 & 4.45 & 4.47 & 4.76 & 4.71 \\
\hline & $\mathrm{T} 2$ & 4.47 & 4.41 & 4.44 & 4.85 & $4.86^{\mathrm{a}}$ \\
\hline \multirow[t]{2}{*}{-know about how medications affect children's oral health. } & $\mathrm{T} 1$ & 4.51 & 4.42 & 4.39 & 4.73 & 4.40 \\
\hline & $\mathrm{T} 2$ & 4.50 & 4.40 & 4.42 & 4.82 & 4.80 \\
\hline \multirow{4}{*}{$\begin{array}{l}\text {-know about how medical tx/interventions affect children's } \\
\text { oral health. } \\
\text {-know the signs and symptoms of dental disease in children. }\end{array}$} & $\mathrm{T} 1$ & 4.58 & 4.35 & 4.43 & 4.72 & 4.60 \\
\hline & $\mathrm{T} 2$ & 4.48 & 4.32 & 4.37 & 4.88 & $4.80^{\mathrm{a}}$ \\
\hline & $\mathrm{T} 1$ & $4.50^{*}$ & 4.31 & 4.51 & 4.82 & 5.00 \\
\hline & T2 & 4.28 & 4.36 & 4.34 & 4.85 & 5.00 \\
\hline \multirow{2}{*}{$\begin{array}{l}\text { Index } 1 \\
\text { (Cronbach alpha }=0.916 / 0.931)\end{array}$} & $\mathrm{T} 1$ & 4.52 & 4.45 & 4.47 & 4.73 & $4.83^{\mathrm{a}}$ \\
\hline & $\mathrm{T} 2$ & 4.41 & 4.44 & 4.44 & 4.86 & 4.81 \\
\hline \multicolumn{7}{|l|}{$\begin{array}{l}\text { Factor 2: Importance of clinical skills. } \\
\text { It is important that nurses: }\end{array}$} \\
\hline \multirow[t]{2}{*}{-can perform oral screenings. } & $\mathrm{T} 1$ & 3.85 & 3.85 & 3.75 & $4.39 * *$ & 4.57 \\
\hline & $\mathrm{T} 2$ & 4.03 & 3.92 & 4.03 & 4.73 & $4.29^{a}$ \\
\hline \multirow[t]{2}{*}{-can perform oral hygiene procedures. } & T1 & $3.12^{* *}$ & 3.33 & 3.50 & $4.31^{* * *}$ & 4.14 \\
\hline & $\mathrm{T} 2$ & 3.54 & 3.54 & 3.75 & 4.75 & 4.14 \\
\hline \multirow[t]{2}{*}{-can provide oral health education. } & $\mathrm{T} 1$ & 3.77 & 3.85 & 3.89 & $4.56^{*}$ & 4.29 \\
\hline & $\mathrm{T} 2$ & 3.89 & 3.95 & 4.03 & 4.81 & 4.43 \\
\hline -can perform caries risk assessment. & T1 & $3.08^{* *}$ & 3.46 & $3.53^{*}$ & 4.52 & 4.14 \\
\hline & $\mathrm{T} 2$ & 3.50 & 3.52 & 3.92 & 4.74 & 4.14 \\
\hline -can perform oral hygiene in hospitalized pediatric patients. & $\mathrm{T} 1$ & 3.26 & 3.48 & 3.66 & 4.61 & 4.43 \\
\hline & $\mathrm{T} 2$ & 3.42 & 3.65 & 3.77 & 4.82 & 4.00 \\
\hline -can perform an oral assessment with every patient. & T1 & $3.55^{*}$ & 3.81 & 3.83 & $4.24 * *$ & $4.43^{\mathrm{a}}$ \\
\hline & $\mathrm{T} 2$ & 3.91 & 3.88 & 4.00 & 4.64 & 4.14 \\
\hline Index 2 & $\mathrm{~T} 1$ & $3.44^{*}$ & 3.65 & 3.71 & $4.44^{* * *}$ & $4.33^{\mathrm{a}}$ \\
\hline (Cronbach alpha=0.903/0.954) & $\mathrm{T} 2$ & 3.71 & 3.75 & 3.91 & 4.76 & 4.19 \\
\hline Factor 3: Importance to consider oral health in clinical setting. & & & & & & \\
\hline It is important that nurses: & & & & & & \\
\hline -learn about oral health issues in clinical settings. & T1 & 4.43 & 4.41 & 4.31 & $4.52 *$ & 4.60 \\
\hline & $\mathrm{T} 2$ & 4.30 & 4.42 & 4.28 & 4.79 & 4.60 \\
\hline -learn about oral health issues in continuing education. & $\mathrm{T} 1$ & 4.15 & 4.21 & 4.19 & $4.27^{*}$ & 4.20 \\
\hline & $\mathrm{T} 2$ & 4.24 & 4.19 & 4.11 & 4.58 & 4.40 \\
\hline -collaborate with dental care providers. & $\mathrm{T} 1$ & 4.30 & 4.27 & 4.33 & 4.64 & 4.60 \\
\hline & $\mathrm{T} 2$ & 3.36 & 4.40 & 4.31 & 4.82 & 4.40 \\
\hline -use an oral assessment guide. & $\mathrm{T} 1$ & 3.80 & 3.94 & 3.81 & $4.46^{*}$ & $4.20^{\mathrm{a}}$ \\
\hline & $\mathrm{T} 2$ & 4.04 & 3.98 & 4.03 & 4.70 & 4.00 \\
\hline -see that oral health is as important as systemic health. & $\mathrm{T} 1$ & 4.29 & 4.37 & 4.39 & 4.61 & 4.80 \\
\hline & $\mathrm{T} 2$ & 4.30 & 4.47 & 4.31 & 4.67 & 4.20 \\
\hline Index 3 & $\mathrm{~T} 1$ & 4.19 & 4.24 & 4.21 & $4.50^{* *}$ & $4.48^{\mathrm{a}}$ \\
\hline (Cronbach alpha $=0.824 / 0.875)$ & $\mathrm{T} 2$ & 4.25 & 4.29 & 4.21 & 4.71 & 4.28 \\
\hline Factor 4: Importance of skills to recognize. & & & & & & \\
\hline -dental caries. & T1 & $3.50 *$ & 3.59 & $3.58^{*}$ & $4.27 * *$ & 4.80 \\
\hline & $\mathrm{T} 2$ & 3.79 & 3.82 & 3.97 & 4.72 & 5.00 \\
\hline -gingivitis. & T1 & 3.57 & 3.59 & 3.64 & $4.46^{*}$ & 4.40 \\
\hline & $\mathrm{T} 2$ & 3.76 & 3.66 & 3.94 & 4.67 & 4.20 \\
\hline -abnormal intraoral pathologies. & T1 & 3.86 & 3.86 & 3.75 & $4.39 *$ & 4.60 \\
\hline & $\mathrm{T} 2$ & 3.97 & 3.94 & 3.92 & 4.70 & 4.20 \\
\hline Index 4 & T1 & 3.64 & 3.67 & 3.66 & $4.37^{* *}$ & $4.60^{\mathrm{a}}$ \\
\hline$($ Cronbach alpha $=0.913 / 0.926)$ & $\mathrm{T} 2$ & 3.84 & 3.79 & 3.94 & 4.70 & 4.47 \\
\hline $\begin{array}{l}\text { Note: Response options ranged from } 1=\text { disagree strongly to } 5=\text { agree stro } \\
{ }^{*} p<0.05 ;{ }^{* *} p<0.01 ;{ }^{* * *} p<0.001 \\
{ }^{2} p<0.05 \text { for main effect "Type of respondent: D3 vs. nursing students vs. }\end{array}$ & ent & & & & & \\
\hline
\end{tabular}


importance ratings. Nursing students' overall importance ratings of the statements that nurses have clinical skills (Factor 2), consider oral health in clinical settings (Factor 3), and can recognize oral disease (Factor 4) as well as individual responses to two statements of the items loading on Factor 1 ("It is important that nurses learn about oral health issues in school" and "It is important that nurses know about the relationship between oral health and systemic health") increased significantly from $\mathrm{T} 1$ to T2 as predicted. However, the D3 students did not change their importance ratings in general. For the D3s, only two single importance ratings changed as predicted. These were the answers to the statements "It is important that nurses can perform caries risk assessment" and "It is important that nurses can recognize caries."

One unpredicted finding was the fact that D1 students' importance ratings of nurses' having clinical skills actually increased as well as their ratings of the statement that it is important that nurses can recognize caries. However, their single ratings of the importance that nurses know about the relationship between oral and systemic health and that they know the signs and symptoms of dental disease in children actually decreased.

In addition to asking the dental and nursing students and residents to rate the importance of nurses' being engaged in twenty oral health-related issues, the groups also responded to the RIPLS at T1 and
$\mathrm{T} 2$ in its three areas: Teamwork and Collaboration, Professional Identity, and Roles and Responsibilities. ${ }^{19}$ The five groups of respondents did not differ in responses to the items loading on the three factors at T1 (Table 5). However, after the rotation (T2), the nursing students showed a significantly higher RIPLS score related to Teamwork and Collaboration and to Professional Identity than the respondents in the other four groups. A second finding was that overall the RIPLS scores related to Professional Identity decreased from $\mathrm{T} 1$ to $\mathrm{T} 2$. A third finding was that the interaction effect between "Time" and "Type of respondent" for the third dimension (Roles and Responsibilities) was significant. While the D1 and D2 students and the residents increased their RIPLS scores related to their role, the D3s and the nursing students decreased their RIPLS scores related to this third factor.

In response to the question how the RIPLS scores would be related to the importance ratings of nurses' having oral health-related knowledge and skills, the Teamwork and Collaboration factor and the Professional Identity factor were significantly correlated with all four importance rating factors at T1 and at T2 (Table 6). The more important the respondents rated the statements concerning nurses' having oral health-related knowledge and skills, the more they were ready for interprofessional learning related to these two factors. However, the relationships between the importance-related responses and

Table 5. Average Readiness for Interprofessional Learning Scale (RIPLS) indices of dental and nursing students and pediatric dentistry residents at Time 1 and Time 2

\begin{tabular}{|c|c|c|c|c|c|c|}
\hline \multirow[b]{2}{*}{ RIPLS Factor } & \multirow[b]{2}{*}{ Time } & \multicolumn{2}{|c|}{ No Rotation } & \multicolumn{3}{|c|}{ Rotation } \\
\hline & & $\begin{array}{c}\text { D1 } \\
\text { Students }\end{array}$ & $\begin{array}{c}\text { D2 } \\
\text { Students }\end{array}$ & $\begin{array}{c}\text { D3 } \\
\text { Students }\end{array}$ & $\begin{array}{l}\text { Nursing } \\
\text { Students }\end{array}$ & $\begin{array}{l}\text { Pediatric } \\
\text { Dentistry } \\
\text { Residents }\end{array}$ \\
\hline \multirow{2}{*}{$\begin{array}{l}\text { Factor } 1: \text { Teamwork and Collaboration } \\
(\text { alpha }=0.933 / 0.939)\end{array}$} & $\mathrm{T} 1$ & 4.33 & 4.21 & 4.51 & 4.80 & 4.44 \\
\hline & $\mathrm{T} 2$ & 4.31 & 4.21 & 4.28 & 4.83 & $4.36^{\mathrm{b}}$ \\
\hline \multirow{2}{*}{$\begin{array}{l}\text { Factor 2: Professional Identity } \\
(\text { alpha }=0.818 / 0.824)\end{array}$} & $\mathrm{T} 1$ & 3.97 & 3.86 & 4.01 & 4.65 & 4.03 \\
\hline & $\mathrm{T} 2$ & 3.89 & 3.78 & 3.93 & 4.57 & $3.59^{a, b}$ \\
\hline \multirow{2}{*}{$\begin{array}{l}\text { Factor 3: Roles and Responsibilities } \\
\text { (alpha }=0.618 / 0.666)\end{array}$} & T1 & 2.59 & 2.64 & 2.80 & 2.70 & 2.10 \\
\hline & $\mathrm{T} 2$ & $2.86^{\mathrm{d}}$ & 2.85 & 2.49 & 2.50 & $2.30^{c}$ \\
\hline \multicolumn{7}{|c|}{$\begin{array}{l}\text { Note: Response options ranged from } 1=\text { lowest degree of endorsing the factor content to } 5=\text { highest degree of endorsing the factor } \\
\text { content. }\end{array}$} \\
\hline \multicolumn{7}{|l|}{$\begin{array}{l}\text { a } p<0.05 \text { for main effect "Time" } \\
\text { b } p<0.05 \text { for main effect "Type of respondent" } \\
\text { c } p<0.05 \text { for interaction effect "Time x Type of respondent" } \\
\text { d } p<0.05 \text { for post hoc test for comparing D1 students' respons }\end{array}$} \\
\hline
\end{tabular}


the RIPLS scores related to the third factor (Roles and Responsibilities) did not show a consistent pattern of relationships.

Table 7 shows the D3s' and nursing students' evaluations of their rotation in the pediatric dental clinic. Both D3s and nursing students enjoyed their rotation and on average agreed strongly that they learned a lot about pediatric dentistry. The nursing students, however, agreed more strongly that they learned information about oral health they are likely to use and should use in their careers. In addition, both dental and nursing students agreed that they learned clinical skills they are likely to use in their careers, that the dental clinic rotation in the children's dental clinic was a valuable experience for them, and that a clinical rotation in the children's clinic is a valuable experience for nursing students in general.
However, the two groups disagreed/were neutral in response to the statement that the things they learned in the rotation they could have more easily learned in a lecture.

\section{Discussion}

Developing IPE experiences for students in health professions schools is clearly a timely topic as the recently published workshop summary entitled Interprofessional Education for Collaboration showed. ${ }^{22}$ The authors of that report argued that IPE provides students with opportunities to improve their ability to communicate and collaborate with other health care providers and to develop leadership qualities and respect for each other - which above all

Table 6. Correlation between professional importance ratings related to nurses' having oral health-related knowledge and skills and Readiness for Interprofessional Learning Scale (RIPLS) indices at Times 1 and 2

\begin{tabular}{|c|c|c|c|c|}
\hline \multirow[b]{2}{*}{ Factor } & \multirow[b]{2}{*}{ Time } & \multicolumn{3}{|c|}{ RIPLS } \\
\hline & & $\begin{array}{c}\text { Factor 1: } \\
\text { Teamwork and } \\
\text { Collaboration }\end{array}$ & $\begin{array}{c}\text { Factor 2: } \\
\text { Professional } \\
\text { Identity }\end{array}$ & $\begin{array}{c}\text { Factor 3: } \\
\text { Roles and } \\
\text { Responsibilities }\end{array}$ \\
\hline $\begin{array}{l}\text { Factor 1: Importance of nurses' knowing about the } \\
\text { relationship between oral and systemic health }\end{array}$ & $\begin{array}{l}\text { T1 } \\
\text { T2 }\end{array}$ & $\begin{array}{l}0.47^{* *} \\
0.44^{* *}\end{array}$ & $\begin{array}{l}0.39^{* *} \\
0.36^{* *}\end{array}$ & $\begin{array}{l}-0.12^{*} \\
-0.06\end{array}$ \\
\hline Factor 2: Importance of nurses' having clinical skills & $\begin{array}{l}\text { T1 } \\
\text { T2 }\end{array}$ & $\begin{array}{l}0.27^{* *} \\
0.27^{* *}\end{array}$ & $\begin{array}{l}0.26^{* *} \\
0.24^{* *}\end{array}$ & $\begin{array}{c}0.06 \\
0.12^{*}\end{array}$ \\
\hline $\begin{array}{l}\text { Factor 3: Importance of nurses to consider oral health } \\
\text { in clinical settings }\end{array}$ & $\begin{array}{l}\text { T1 } \\
\text { T2 }\end{array}$ & $\begin{array}{l}0.44^{* *} \\
0.47^{* *}\end{array}$ & $\begin{array}{l}0.38^{* *} \\
0.36^{* *}\end{array}$ & $\begin{array}{l}-0.06 \\
-0.02\end{array}$ \\
\hline $\begin{array}{l}\text { Factor 4: Importance of nurses' having the skills to } \\
\text { detect oral diseases }\end{array}$ & $\begin{array}{l}\text { T1 } \\
\text { T2 }\end{array}$ & $\begin{array}{l}0.26^{* *} \\
0.23^{* *}\end{array}$ & $\begin{array}{l}0.21^{* *} \\
0.20^{* *}\end{array}$ & $\begin{array}{l}0.004 \\
0.11^{*}\end{array}$ \\
\hline$* \mathrm{p}<0.05 ; * * \mathrm{p}<0.001$ & & & & \\
\hline
\end{tabular}

Table 7. Dental and nursing students' evaluations after the clinical rotation: mean (standard deviation) for each group

\begin{tabular}{|c|c|c|c|}
\hline Evaluation Statement & $\begin{array}{c}\text { D3 } \\
\text { Students } \\
\mathrm{N}=40\end{array}$ & $\begin{array}{c}\text { Nursing } \\
\text { Students } \\
N=33\end{array}$ & $\mathrm{p}$ \\
\hline I enjoyed my rotation in the pediatric dental clinic. & $4.40(0.632)$ & $4.24(1.091)$ & 0.466 \\
\hline I learned a lot about pediatric dentistry during this rotation. & $4.55(0.597)$ & $4.76(0.502)$ & 0.111 \\
\hline I learned information about oral health that I am likely to use in my career. & $4.45(0.552)$ & $4.82(0.392)$ & 0.001 \\
\hline $\begin{array}{l}\text { The nursing students learned information about oral health that they should use } \\
\text { in their career. }\end{array}$ & $3.73(0.960)$ & $4.82(0.392)$ & $<0.001$ \\
\hline I learned clinical skills that I am likely to use in my career. & $4.48(0.599)$ & $4.06(1.273)$ & 0.093 \\
\hline A clinical rotation (children's) dental clinic is a valuable experience for me. & $4.60(0.591)$ & $4.21(1.083)$ & 0.071 \\
\hline $\begin{array}{l}\text { A clinical rotation in a children's dental clinic is a valuable experience for nursing } \\
\text { students. }\end{array}$ & $3.83(1.035)$ & $4.21(1.083)$ & 0.124 \\
\hline All nursing students should rotate through a (children's) dental clinic. & $3.55(1.154)$ & $4.00(0.968)$ & 0.079 \\
\hline The things I learned could have been more easily learned in a lecture. & $2.38(1.275)$ & $2.61(1.345)$ & 0.455 \\
\hline
\end{tabular}

Note: Response options ranged from $1=$ disagree strongly to $5=$ agree strongly. 
will result in better and safer patient care and public health. ${ }^{23-25}$

In dentistry, IPE has received increasingly more attention since the Commission on Dental Accreditation (CODA) added two new predoctoral accreditation standards related to IPE, implemented on July 1,2013 . These standards state that "the dental school must show evidence of interaction with other components of the higher education, health care education, and/or health care delivery systems" (Standard 1-9) and that "Graduates must be competent in communicating and collaborating with other members of the health care team to facilitate the provision of health care" (Standard 2-19). ${ }^{26}$ An overview of dental schools' efforts related to these new standards published in 2012 by Formicola et al. reported that not all dental schools were meeting these standards at that time. ${ }^{17}$ While those authors outlined the benefits of IPE, they pointed out that the best methods for integrating IPE into health professions curricula are not as clearly developed. Evaluating the outcomes of newly developed IPE efforts is therefore important and was the overarching focus of our study.

Concerning the effects of this IPE experience on nursing students, the data showed a positive effect of the rotation on their own oral health-related behavior. The average frequency of tooth brushing increased, as well as the percentage of students who were comfortable with visiting a dentist. In addition, these students reported that they had had a first dental visit earlier in life after the rotation compared to before the rotation. It is difficult to interpret this finding. One possible explanation might be that the students discussed their experiences with their primary caregivers and found out that their first dental visits had been earlier than they thought. However, this finding might also be related to having an increased understanding of the importance of taking children for a first dental visit early in life, which may have affected the estimate of the time of their own first visit in the form of "wishful thinking."

An assessment of the nursing students' knowledge before the rotation showed that they had a general understanding that medical conditions, medications, and medical treatments can affect oral health and that oral health can affect systemic health. However, more specific oral health-related knowledge and perceptions of whether they can recognize oral diseases were rather rudimentary. The outcome data showed a significant improvement of these students' knowledge and perceptions of their oral health-related skills. These findings are consis- tent with the results of a study with pediatric nurse practitioner students, whose participation in an IPE program had also resulted in an increase of their oral health-related knowledge. ${ }^{27}$ The data from our study also allow us to consider which oral health-related knowledge might be included in nursing curricula and then develop recommendations concerning which other oral health-related issues need to be integrated to allow positive interprofessional collaboration and communication.

Concerning our second objective to assess how dental and nursing students' attitudes towards the importance of nurses' having oral health-related knowledge and skills and readiness for interprofessional learning would change as a function of the rotation, the data showed a not so consistent picture. As predicted, the nursing students' attitudes related to the importance of nurses' having clinical skills, considering oral health in clinical settings, and having skills to recognize oral disease improved significantly to a very positive level. However, the dental students' attitudes did not improve overall. Instead, their attitudes related to only one specific aspect of nurses' involvement with pediatric oral health issues improved. This issue is related to nurses' being able to perform caries risk assessments in children and to recognize caries in children. This finding deserves attention in two ways. First, in dental education, a considerable amount of time in classroom-based and clinical settings is spent on caries risk assessment and the detection of caries. This increased attention may have alerted the D3s to the fact that it is important for nursing students and ultimately nurses to be involved in these activities. Second, childhood caries received such a considerable amount of attention ${ }^{1}$ that the D3s might have become increasingly more aware of the importance of interprofessional collaboration for solving this challenge. In any case, their increased importance ratings show that change in dental students' attitudes can be achieved in certain areas of concern. It might be important to involve dental students in hospital settings on pediatric wards or in outpatient pediatric clinics to allow them to gain a better appreciation of the possibilities for engaging nurses other than caries-related oral health promotion efforts for pediatric patients.

One unexpected finding was the improvement of D1 students' attitudes concerning the importance of nurses' having clinical skills related to oral health issues and to recognizing caries in children. These outcomes point to the possibility that classroombased education during the D1 year could improve 
these students' attitudes and thus might facilitate their later participation in IPE.

In addition to analyzing attitudinal changes related to the importance of nurses' involvement in pediatric oral health promotion efforts, the readiness for interprofessional learning for all respondents was assessed, based on their RIPLS scores. The data showed that the nursing students had the highest RIPLS scores related to Teamwork and Collaboration as well as to Professional Identity after their rotation. This finding reiterates the fact that the rotation for the nurses - although only one week long — was quite effective in not only increasing their knowledge and improving their attitudes but also in increasing their readiness for interprofessional learning. However, the finding that the Professional Identity-related RIPLS scores decreased overall over time for all students deserves attention. Future research should try to gain a better understanding of how to improve the readiness for interprofessional learning of students in all health professions. Possible educational interventions could be to expose these students to the professional activities of other health professions students/professionals and thus increase their interest to learn more about these other providers' professional life.

An interesting pattern of results was found concerning the Roles and Responsibilities-related RIPLS scores. While D1 and D2 students' and residents' readiness to learn about this issue in IPE increased, the scores of both D3 and nursing students decreased. It seems important to consider how to integrate rolerelated experiences into IPE programs to challenge students to consider the importance of learning more about these issues.

The fact that consistent correlations were found between the Teamwork and Collaboration aspect and Professional Identity aspect of the RIPLS scores and the four importance factors supports the argument that positive learning experiences can increase students' readiness for additional IPE experiences. However, the lack of consistent relationships between the four importance factors and the role-related RIPLS scores again points to the importance of considering role-related issues in curricular interventions as well as in pedagogical considerations.

Overall, this IPE program was positively evaluated by the D3 and nursing students. The fact that both groups did not agree that what they learned in this rotation could have been more easily learned in a lecture is noteworthy because it shows that students are aware of the importance of clinical interactions when engaging in IPE. Nevertheless, it seems worthwhile to consider increasing the time spent in interprofessional interactions and seeking out opportunities for dental students to spend time in other health care settings.

This study has the limitation of being based on the results of one program at one dental school. However, these findings can show the effectiveness of an IPE experience for nursing students and can point to needed future research concerning making IPE programs more effective for dental students and pediatric residents.

\section{Conclusion}

The nursing students who participated in a clinical pediatric dentistry IPE experience with third-year dental students and pediatric dentistry residents improved their oral health-related behavior, knowledge, and attitudes related to the importance of nurses' being involved in oral health promotion efforts for children. Dental students participating in this rotation also improved their attitudes related to the importance of nurses' engaging in caries risk assessment and recognizing caries. These findings point to the need to explore how to concretely involve dental students in gaining a better understanding of the role nurses can play in oral health promotion efforts. In addition, the Teamwork and Collaboration and the Professional Identity RIPLS scores were clearly related to students' importance ratings of nurses' involvement in oral health promotion efforts for pediatric patients. Overall, this IPE program was very well received by both third-year dental and nursing students.

\section{REFERENCES}

1. Oral health in America: a report of the surgeon general. Rockville, MD: U.S. Department of Health and Human Services, National Institutes of Health, National Institute of Dental and Craniofacial Research, 2000.

2. Simon TD, Berry J, Feudtner C, et al. Children with complex chronic conditions in inpatient hospital settings in the United States. Pediatrics 2010;126(4):647-55.

3. Kite K, Pearson L. A rationale for mouth care: the integration of theory with practice. Intensive Crit Care Nurse 1995;11(2):71-6.

4. Barnett J. A reassessment of oral health care. Prof Nurse 1991;6(12):703-8.

5. Nicopoulos M, Brennan MT, Kent ML, et al. Oral health needs and barriers to dental care in hospitalized children. Spec Care Dent 2007;27(5):206-11.

6. Blevins JY. Oral health care for hospitalized children. Pediatr Nurse 2011;37(5):229-35. 
7. Foster H, Fitzgerald J. Dental disease in children with chronic illness. Arch Dis Child 2005;90(7):703-8.

8. McNeill HE. Biting back at poor oral hygiene. Intensive Crit Care Nurse 2000;16(6):367-72.

9. Gillcrist JA, Brumley DE, Blackford JU. Community socioeconomic status and children's dental health. J Am Dent Assoc 2001;132(2):216-22.

10. Vargas CM, Crall JJ, Schneider DA. Sociodemographic distribution of pediatric dental caries: NHANES III, 198894. J Am Dent Assoc 1998;129(9):1229-38.

11. Boyle S. Assessing mouth care. Nurs Times 1992;88(15):4.

12. Miller R, Rubinstein L. Oral health care for hospitalized patients: the nurse's role. J Nurs Educ 1987;26(9):362-6.

13. Adams R. Qualified nurses lack adequate knowledge related to oral health, resulting in inadequate oral care of patients on medical wards. J Adv Nurs 1996;24:552-60.

14. Longhurst RH. A cross-sectional study of the oral health care instruction given to nurses during their basic training. Br Dent J 1998;184(9):453-7.

15. Southern H. Oral care in cancer nursing: nurses' knowledge and education. J Adv Nurs 2007;57(6):631-8.

16. Costello T, Coyne I. Nurses' knowledge of mouth care practices. Br J Nurs 2008;17(4):264-8.

17. Formicola AJ, Andrieu SC, Buchanan JA, et al. Interprofessional education in U.S. and Canadian dental schools: an ADEA team study group report. J Dent Educ 2012;76(9):1250-68.

18. Ajzen I, Fishbein M. Attitude-behavior relations: a theoretical analysis and review of empirical research. Psych Bull 1977;84(5):888-918.
19. Parsell G, Bligh J. The development of a questionnaire to assess the readiness of health care students for interprofessional learning (RIPLS). Med Educ 1999;33(2):95-120.

20. McDonald RE, Avery DR. Dentistry for the child and adolescent. $9^{\text {th }}$ ed. Maryland Heights, MO: Mosby Elsevier, 2011.

21. DeVellis RF. Scale development: theory and applications. Thousand Oaks, CA: Sage, 2003.

22. Institute of Medicine. Interprofessional education for collaboration. Washington, DC: National Academies Press, 2013.

23. Campbell SM, Hann M, Hacker J, et al. Identifying predictors of high quality care in English general practice: observational study. Br Med J 2001;323(7316):784-7.

24. Stevenson K, Baker R, Farooqi A, et al. Features of primary health care teams associated with successful quality improvement of diabetes care: a qualitative study. Fam Pract 2001;18(1):21-6.

25. Mukamel DB, Temkin-Greener R, Delavan R, et al. Team performance and risk-adjusted health outcomes in the program of all-inclusive care for the elderly (PACE). Gerontologist 2006;46(2):227-37.

26. Commission on Dental Accreditation. Accreditation standards for dental education programs. 2013. At: www.ada. org/sections/educationAndCareers/pdfs/predoc_2013.pdf. Accessed: October 20, 2013.

27. Golinveaux J, Gerbert B, Cheng J, et al. Oral health education for pediatric nurse practitioner students. J Dent Educ 2013;77(5):580-9. 